\title{
IMMUNOFLUORESCENT STUDIES ON MAMMALIAN SPERMATOZOA: ANTIGENIC RELATIONSHIP BETWEEN HUMAN, BULL AND RABBIT SPERMATOZOA
}

\author{
K. BROGAARD HANSEN \\ University Maternity Hospital and Institute of Medical Microbiology, \\ University of Aarhus, Denmark
}

(Received 10th March 1971, accepted 12th October 1971)

\begin{abstract}
Summary. Human sera, which had revealed a number of sperm antibodies in indirect immunofluorescence tests with human spermatozoa, were tested against bull and rabbit spermatozoa. Similar staining patterns were found, and the slightly different extension of the various structures in these spermatozoa provided strong supporting evidence for the previous assumption that different antibodies react with (1) the anterior part of the acrosome, (2) the equatorial segment, (3) the postnuclear cap, and (4) the tail. A close antigenic relationship between the three species was found for the equatorial antigen and the antigen in the postnuclear cap. However, in absorption experiments, the commonly occurring antibody staining the anterior part of the acrosome in heterologous spermatozoa appeared to be different from that responsible for such staining in human spermatozoa. A similar phenomenon seemed to underlie the tail reactions of homologous and heterologous spermatozoa.
\end{abstract}

\section{INTRODUGTION}

Electron microscope studies have led to the discovery of several ultrastructural similarities between human and other mammalian spermatozoa (Fawcett, 1958, 1970; Hancock, 1966). The acrosome, its equatorial segment and the postnuclear cap have been described in the spermatozoa of man (Pedersen, 1969), bulls (Blom \& Birch-Andersen, 1961; Saacke \& Almquist, 1964; Blom \& Birch-Andersen, 1965) and rabbits (Hadek, 1963; Bedford, 1964).

The use of spermatozoa as antigen in an immunofluorescence technique (IFT) has led to the description over the last decade of several different antibodies, with characteristic staining patterns (see review by Hjort \& Hansen, 1971). Some of these patterns appeared to be located in the acrosome, mid-piece, or main-piece. Using washed methanol-fixed hur. s spermatozoa as antigen in the indirect IFT, Hjort \& Hansen (1971) demonstrated antibodies, in women's sera, against antigens localized in different places on human spermatozoa. The characteristic patterns of fluorescence which were often found in various combinations had the following four localizations: (1) a crescent-shaped figure involving the anterior half of the head of the spermatozoon, (2) a well- 
defined band across the head in its equatorial region (Pl. 2, Fig. 5), (3) a pattern composed of two fluorescent bands covering the posterior part of the head from the equator to the neck region (a region of weaker staining between the two bands produced a bowl-like figure-see Pl. 2, Fig. 8), and (4) the main-piece, which was the only part of the tail to fluoresce in typical cases. Antibodies against antigens on the first two locations were often found together (Pl. 1, Fig. 1). There can be no doubt that two different antigens were involved, since certain sera produced only one of the two patterns of fluorescence. The presence of three different antigens on the heads of human spermatozoa was corroborated by Hansen \& Hjort (1971). The extent of the staining reactions in the indirect IFT indicated that the three antigens were located in the anterior part of the acrosome, in the equatorial segment of the acrosome and in the postnuclear cap (Hjort \& Hansen, 1971).

It was the purpose of this investigation to study whether cross-reactions exist between the above-mentioned antigens in human spermatozoa and the somewhat larger spermatozoa of the bull and rabbit using human antisera in an indirect IFT. As the antigens appear to be organ-specific (Hjort \& Hansen, 1971), cross-reactivity may occur (Kabat \& Mayer, 1961). The appearance of similar staining patterns in human, bull and rabbit spermatozoa may throw light on the structures underlying the various locations of the antigens, because of the slightly different extent of the acrosome, equatorial segment and postnuclear cap in these three types of spermatozoa.

\section{MATERIALS AND METHODS}

Sera from the female partner of infertile couples were used as the source of antibodies. These sera were chosen on the basis of their content of antibodies against human spermatozoa, which was tested in fourfold dilutions by an indirect IFT. The use of known positive sera ensured that the different antigens were present in the spermatozoa. The content of antibodies against bull and rabbit spermatozoa was determined by the same technique with the respective spermatozoa serving as antigen. This part of the study was carried out on the same day by the use of spermatozoa from one ejaculate for each species.

The spermatozoa used in this study were obtained from apparently normal ejaculates of the male partners of infertile couples. Individual ejaculates contained more than $40 \times 10^{6}$ spermatozoa/ml and $1 \mathrm{hr}$ after ejaculation at least $60 \%$ of the spermatozoa were considered to be motile and $70 \%$ appeared morphologically normal. Bull spermatozoa were obtained from ejaculates of a fertile bull. The sperm concentration of the ejaculates was 1500 to $2100 \times 10^{6} / \mathrm{ml}$. Rabbit ejaculates with a sperm concentration of $400 \times 10^{6} / \mathrm{ml}$ were collected from a healthy rabbit by means of an artificial vagina (Koefoed-Johnsen, 1964). None of the ejaculates used revealed any spontaneous agglutination of the spermatozoa. The spermatozoa were stored at $4^{\circ} \mathrm{C}$ and used within $24 \mathrm{hr}$ of ejaculation.

The IFT was performed as previously described (Hjort \& Hansen, 1971). The spermatozoa in $0.1 \mathrm{ml}$ semen were washed twice in saline and then, irrespective of their size, suspended in saline so that a final concentration of $10 \times 10^{6}$ 
spermatozoa/ml was obtained. A drop of this suspension was allowed to dry on a slide, which was then fixed in absolute methanol for $30 \mathrm{~min}$. A drop of the serum or serum dilution was placed on the slide and allowed to remain there for $1 \mathrm{hr}$. Fluorescein-conjugated horse anti-human immunoglobulin (Blood Transfusion Laboratory, Amsterdam) with antibodies against human IgG, IgA and IgM was applied after washing in phosphate-buffered saline (pH 7.2) and removed again $30 \mathrm{~min}$ later. Finally, the preparations were mounted in a mixture of buffer and glycerol. Staining reactions were read under dark-field illumination on a Zeiss fluorescence microscope with a HBO-200 lamp and interference filters specially adjusted to fluorescein isothiocyanate.

The semen samples were tested with fluorescein-conjugated anti-human immunoglobulin without previous treatment with serum, and all samples revealed completely negative reactions.

In order to investigate further the possible relationship between antigens of the acrosome and tail of human and bull spermatozoa, absorption experiments were performed using specially chosen sera, human adrenal extract, human spermatozoa and bull spermatozoa. Human adrenal tissue was macerated in a homogenizer employing $3 \mathrm{ml}$ saline/g of tissue. The fat was then removed by centrifugation before the extract was used for absorption. The spermatozoa were separated from seminal plasma by centrifugation, washed twice in saline and, thereafter, suspended in saline to a final concentration of $500 \times 10^{6}$ spermatozoa $/ \mathrm{ml}$. Absorption was performed by mixing equal portions of undiluted serum and adrenal extract or sperm suspension, allowing the mixture to stand at $37^{\circ} \mathrm{C}$ for $1 \mathrm{hr}$ and then at $4^{\circ} \mathrm{C}$ for $18 \mathrm{hr}$. After centrifugation, the supernatant was employed as the second layer in the indirect IFT.

\section{RESULTS}

The staining patterns produced by each of the twelve sera when tested against the three different types of spermatozoa used as antigen are shown in Table 1. In addition, the titre of the fluorescence reaction corresponding to each of the four localizations on the spermatozoa on titration of sera diluted fourfold is also given. Selected sera with either weak or strong reactions against the antigens of the four locations on the human spermatozoa were examined. A single serum (No. 7) had antibodies against all four antigens, i.e. fluorescence of the entire sperm head with the exception of the neck region was produced. Two sera (Nos. 11 and 12) caused no staining of human spermatozoa.

The patterns of fluorescence of the heads of bull spermatozoa could be localized to three areas, as with human spermatozoa. Staining affected approximately half of the anterior part of the head (PI. 1, Figs. 3 and 4), a clear concave demarcation occurring posteriorly. The equatorial zone revealed a sharply demarcated band (Pl. 2, Fig. 6) which was convex anteriorly and slightly convex posteriorly on viewing the flat surface of the head, i.e. the band was widest at the middle. The curvature of the anterior border of the equatorial band corresponded to the concave posterior border of staining of the anterior portion of the head (Pl. 1, Fig. 2 and Pl. 2, Fig. 6). On the posterior portion of the heads of the bull spermatozoa (Pl. 1, Fig. 4 and Pl. 2, Fig. 9), a staining 


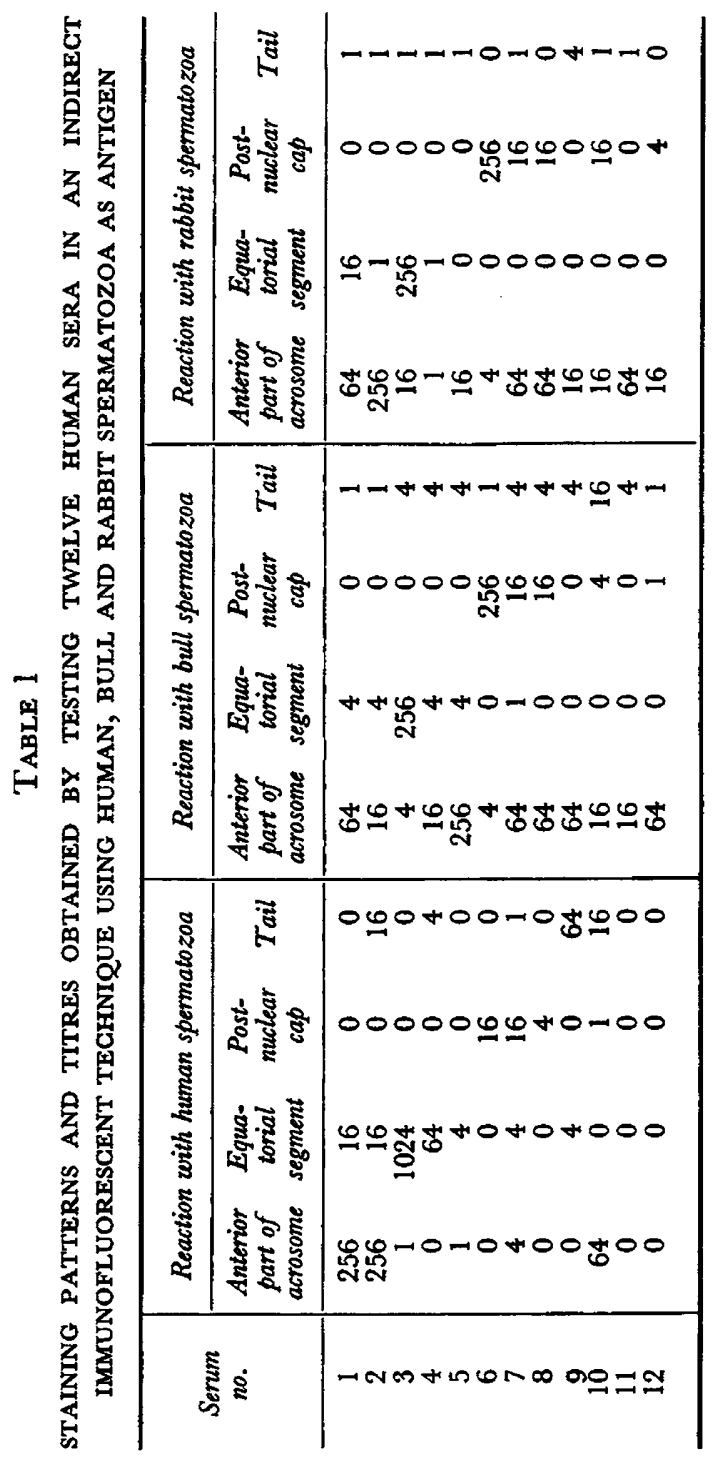


PI..III: I
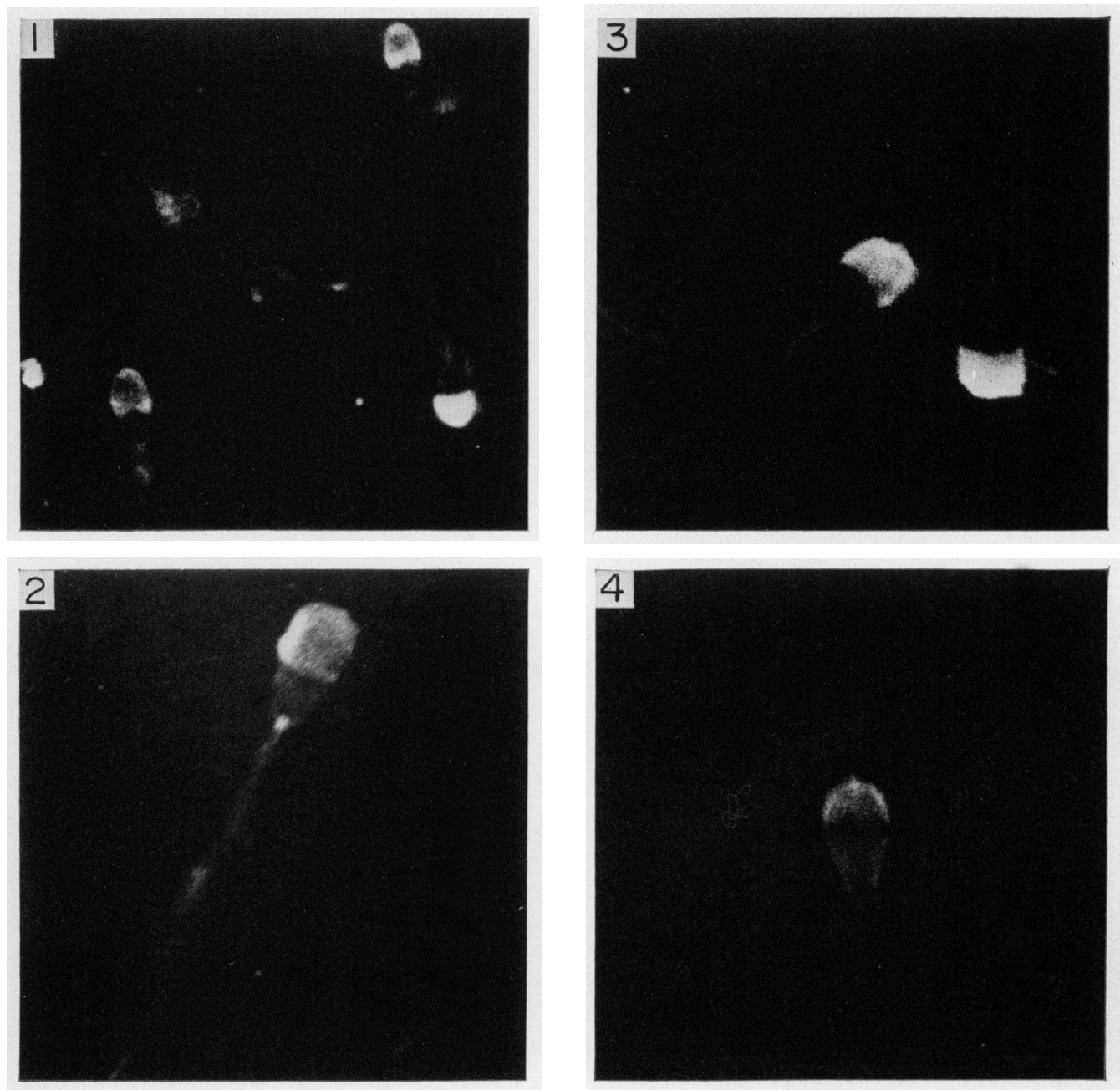

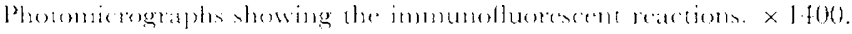

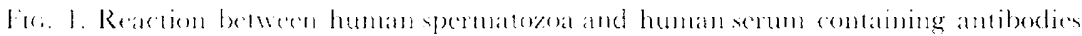

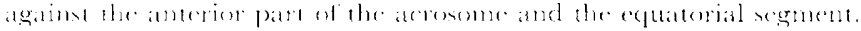

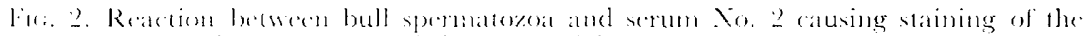

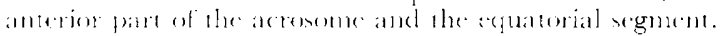

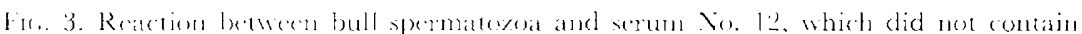

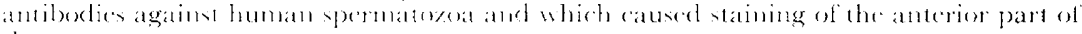
lhe acromermie.

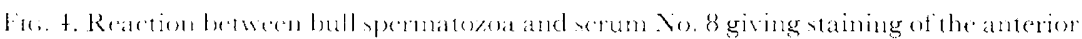

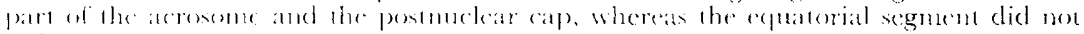
lain. 

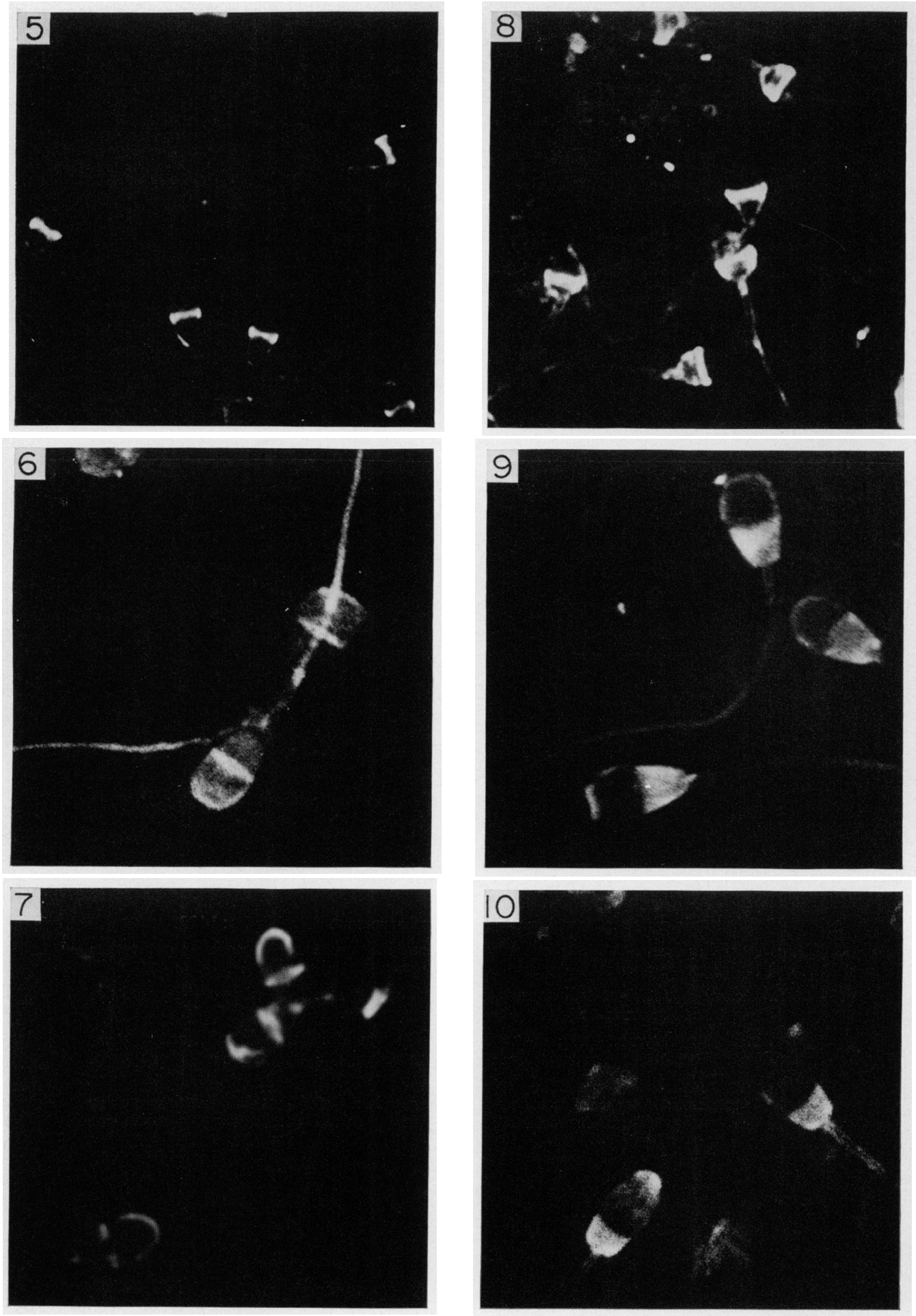
pattern was seen which was bounded anteriorly by a slightly concave line and posteriorly by a straight line. The patterns of fluorescence described here corresponded exactly to the localization of structures under the cell membrane of a bull spermatozoon (Text-fig. 1). The staining of the anterior portion of the

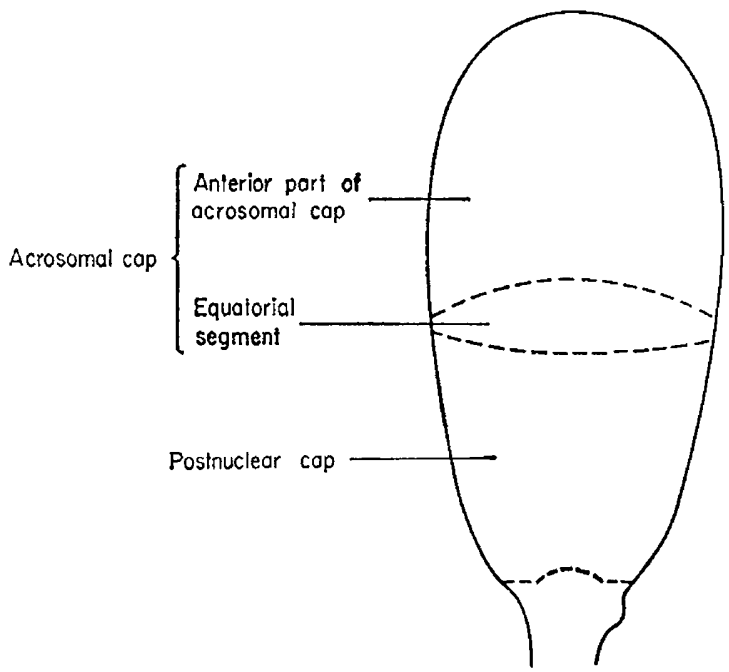

TEXT-FIG. 1. Schematic sketch of the structures under the cell membrane of the head of a bull spermatozoon. Modified after Blom \& Birch-Andersen (1965).

head had the same extent as the anterior thick part of the acrosome; the staining of the equator had the same geometrical form as the equatorial segment, while that of the posterior portion of the head was confined to the same area as the postnuclear cap.

The patterns of fluorescence of the heads of rabbit spermatozoa were also confined to three areas (Pl. 2, Figs. 7 and 10). The band in the equatorial zone, which seems to include the equatorial segment and which is brought out by

\section{EXPLANATION OF PLATE 2}

Photomicrographs showing the immunofluorescent reactions. $\times 1400$.

Fig. 5. Reaction between human spermatozoa and serum No. 3 which caused a strong staining of the equatorial segment.

Fig. 6. Reaction between bull spermatozoa and serum No. 3 which caused a strong staining of the equatorial segment and a weaker staining of the anterior part of the acrosome.

FIG. 7. Reaction between rabbit spermatozoa and serum No. 3 which caused a strong staining of the equatorial segment and staining of the anterior border of the acrosome. Fig. 8. Reaction between human spermatozoa and serum No. 6 containing antibody against the postnuclear cap and giving a bowl-like pattern of fluorescence.

Fig. 9. Reaction between bull spermatozoa and serum No. 6, which caused a marked staining of the postnuclear cap and a weaker staining of the anterior border of the acrosome.

Fig. 10. Reaction between rabbit spermatozoa and serum No. 6, which produced a strong staining of the postnuclear cap and a weaker staining of the anterior part of the acrosome. 
sera which give a similar band on human and bull spermatozoa, lay further posteriorly than for other spermatozoa. The area corresponding to the postnuclear cap was therefore smaller, and the whole acrosome comprised approximately three-quarters of the head when this was seen from its broad surface. The relative sizes of the structures on the head of the rabbit spermatozoon showed good agreement with the sketch made by Bedford (1964) on the basis of electron-microscope observations.

All sera produced staining of the anterior part of the heads of bull and rabbit spermatozoa. This was also the case with sera which did not react with that part of human spermatozoa. Sera with a high titre of antibody against the anterior part of the acrosome of human spermatozoa (Nos. 1, 2 and 10) and sera not containing this antibody (Nos. 8, 9, 11 and 12) produced fluorescence of the same intensity and with approximately the same titre on the anterior part of the heads of bull and rabbit spermatozoa. It is therefore possible that the antibody giving rise to fluorescence of the anterior part of the acrosome of

TAble 2

ABSORPTION EXPERIMENTS EMPLOYING HUMAN SERA GONTAINING ANTIBODY AGAINST THE ANTERIOR PART OF THE ACROSOME OF HUMAN SPERMATOZOA AND SERA WITHOUT ANTIBODY AGAINST HUMAN SPERMATOZOA

\begin{tabular}{|c|c|c|c|c|c|c|c|c|}
\hline \multirow[b]{3}{*}{ Antigen } & \multicolumn{4}{|c|}{$\begin{array}{c}\text { Sera with antibody against the anterior } \\
\text { part of the acrosome of human sper- } \\
\text { matozoa }\end{array}$} & \multicolumn{4}{|c|}{$\begin{array}{c}\text { Sera without antibody against human } \\
\text { spermatozoa }\end{array}$} \\
\hline & \multicolumn{4}{|c|}{ Reaction after absorption with: } & \multicolumn{4}{|c|}{ Reaction after absorption with: } \\
\hline & Saline & $\begin{array}{l}\text { Human } \\
\text { adrenal } \\
\text { extract }\end{array}$ & $\begin{array}{l}\text { Bull } \\
\text { sperma- } \\
\text { tozoa }\end{array}$ & $\begin{array}{l}\text { Human } \\
\text { sperma- } \\
\text { tozoa }\end{array}$ & Saline & $\begin{array}{l}\text { Human } \\
\text { adrenal } \\
\text { extract }\end{array}$ & $\begin{array}{l}\text { Human } \\
\text { sperma- } \\
\text { tozoa }\end{array}$ & $\begin{array}{l}\text { Bull } \\
\text { sperma- } \\
\text { tozoa }\end{array}$ \\
\hline Human spermatozoa & + & - & + & - & - & - & N.D. & - \\
\hline Bull spermatozoa & + & + & - & + & + & + & + & - \\
\hline
\end{tabular}

+ , Fluorescence of the anterior portion of the acrosome was present in the usual titre; -, No fluorescence of the anterior portion of the acrosome was observed. N.D., Not done.

human spermatozoa does not react with bull and rabbit spermatozoa, whereas all sera contain an antibody which combines with the anterior part of the acrosome of these spermatozoa. In addition, heterologous spermatozoa might react with both antibodies in such a way that the patterns of fluorescence overlap in the anterior part of the acrosome.

In order to clarify this problem, absorption experiments were carried out with sera containing antibody against the anterior part of the acrosome of human spermatozoa and sera without antibodies against human spermatozoa. The titres of these sera and the staining of the anterior part of the acrosome of human and bull spermatozoa were determined after absorption with human adrenal extract, human spermatozoa or bull spermatozoa, and compared with the reactions produced when these sera were diluted with saline. As shown in Table 2, the reaction which sera with antibody against the anterior part of the acrosome of human spermatozoa and sera without this antibody gave with the anterior part of the acrosome of bull spermatozoa could be absorbed with bull, 
but not with human, spermatozoa or human adrenal extract. On the other hand, antibody against the antigen of the anterior part of the acrosome of human spermatozoa could be absorbed by human spermatozoa and human adrenal extract, but not by bull spermatozoa. Thus, two different antigenantibody systems seem to exist. The antigen in one system is located on the anterior part of the acrosome of human spermatozoa and reacts with an antibody which is found in some human sera. The other antigen on the anterior part of the acrosome of bull spermatozoa reacts with an antibody in all human sera. Judging from these results, there is no antigenic similarity between human and bull spermatozoa as far as these two antigens are concerned.

The antigen of the equatorial segment of human spermatozoa is related to the antigen with the same localization on bull and rabbit spermatozoa, since the corresponding antibody cross-reacted with these two spermatozoa (Table 1). Seven of the twelve sera had antibodies against the antigen in human spermatozoa; six of these seven sera produced fluorescence of the equatorial segment of bull spermatozoa, whereas only four of the seven stained the equatorial segment of rabbit spermatozoa. The same serum (No. 3) produced the highest titre with all three types of spermatozoa. The antibody appeared to react best with the homologous spermatozoa since the titres of these were higher or equal to the titres with heterologous spermatozoa.

The antigen of the posterior portion of the head of the human spermatozoa also showed an antigenic relationship with heterologous spermatozoa, since all four sera which stained human spermatozoa in this area reacted with the postnuclear cap of bull and rabbit spermatozoa. One serum (No. 12) gave fluorescence of the postnuclear cap in heterologous spermatozoa, but was totally negative when tested against homologous spermatozoa. All four sera which stained the postnuclear cap in both homologous and heterologous spermatozoa gave a titre with the latter which was higher or equal to that obtained with homologous spermatozoa. Thus, this antibody reacted best with heterologous spermatozoa.

All twelve sera gave fluorescence of the tail of bull spermatozoa and nine of the sera gave fluorescence of the tail of rabbit spermatozoa (Table 1). Most of the reactions, however, were of a low titre and fluorescence was variable, at times involving the whole tail, in other cases only the main-piece. Sera with antibody against the tail of human spermatozoa did not give stronger reactions with heterologous spermatozoa than sera without antibody against the tail of human spermatozoa. The reaction with the tail of bull spermatozoa could be absorbed with bull spermatozoa, but not with human spermatozoa. Absorption with bull spermatozoa appeared to weaken the reaction between human sera and homologous spermatozoa, indicating that again several antibody-antigen systems appear to exist.

\section{DISGUSSION}

Spermatozoa in any ejaculate present morphological variations (Mann, 1964). By means of IFT, O'Donnell \& Symons (1970) demonstrated that acrosome staining of bull spermatozoa depended on disruption and shedding of the 
acrosome, and Hansen \& Hjort (1971) revealed that the demonstrability of acrosome antigens in the individual spermatozoa from seventy-six human ejaculates showed considerable differences between the semen samples. In the present study, staining patterns corresponding to the different antigens were not present in all spermatozoa. However, the staining patterns produced by the different antisera could not be explained by morphological or antigenic variations, since one ejaculate for each species was used when testing the sera against heterologous spermatozoa.

Cross-reactions must exist between human, bull and rabbit spermatozoa with regard to the antigens of the equatorial zone and the posterior portion of the head since identical patterns of fluorescence could be produced with the same sera in the three types of spermatozoa in each of the two areas. On the other hand, no antigenic relationship was found between the antigen of the anterior part of the head of human spermatozoa and the anterior part of the head of bull spermatozoa, even though this area could be stained in both types of spermatozoa.

Electron-microscope observations have shown a slight difference in the extent of the histological structures in the three types of spermatozoa and, in view of the fluorescence reactions, there are good grounds to suppose that the areas which stain in all three types of spermatozoa are the anterior part of the acrosome, the equatorial segment and the postnuclear cap. On the basis of the cross-reactions with heterologous spermatozoa, the sharply demarcated band of the equator of human spermatozoa appears to present an antigen in the equatorial segment, and the bowl-like fluorescence of the posterior portion of the head seems to be due to an antigen in the postnuclear cap. The reaction with the latter antigen was strongest in a band just behind the equatorial zone, which must imply that the antigen is found in greatest concentrations in this area. In addition, staining was stronger along the posterior border of the spermatozoa and in a band just in front of the neck region. This may, perhaps, be related to the form of the human spermatozoa in which the light impinges tangentially on this area. Differences in the size, shape and antigenic content of spermatozoa can, together with differences in the extent of the patterns of fluorescence, be partially responsible for the differences in titre which the cross-reacting antibodies show on reaction with human, bull and rabbit spermatozoa.

By means of IFT, Beck, Edwards \& Young (1962) showed that normal sera from various animal species stained the acrosome of homologous and heterologous spermatozoa. A weak reaction could be demonstrated between the sera of normal men and human spermatozoa. Such reactions between normal sera and spermatozoa have since been reported by Edwards (1967), Symons (1967), Johnson (1968), Symons (1968) and O'Donnell \& Symons (1970). The factor in normal serum which possesses the potentiality of reacting with the acrosome in IFT was reported by Edwards (1967) to be found in a titre of 10 to 60 and by Symons (1968) in a titre of 16 to 32 , which corresponds approximately to the observation that all human sera tested in the present study gave fluorescence of the front part of the acrosome of bull and rabbit spermatozoa in titres varying from 1 to 256. This reaction appears to be identical to those previously described between normal sera and the acrosome of heterologous spermatozoa, whereas the staining of the anterior part of the acrosome of human spermatozoa 
produced by some sera is due to another antibody which does not cross-react with bull spermatozoa. In this connection, it should be mentioned that Johnson (1968) found that the natural antibody in normal guinea-pig serum reacting with the acrosome in homologous spermatozoa was an $\mathrm{IgG}_{2}$, whereas Hansen (1972) demonstrated that the antibody in human sera against the anterior part of the acrosome of human spermatozoa was predominantly an IgM.

Fluorescence of the head of heterologous spermatozoa was clearly confined to the anterior part of the acrosome in this study since the staining had the same concave border posteriorly as when the flat surface of the spermatozoa was observed. A strong reaction included the entire anterior thick portion of the acrosome (Pl. 1, Fig. 3).

Symons (1968) observed fluorescence of the main-piece of the tail of heterologous spermatozoa when normal sera were used in IFT. The commonly occurring weak reaction with the tail of bull and rabbit spermatozoa in the present study illustrates the same condition, even though the area of the tail which stained was variable. The reaction with the tail of human spermatozoa, on the other hand, was limited to the main-piece. From the staining reactions, therefore, various antigen-antibody systems seem to exist in the tail area as in the anterior part of the acrosome. This assumption is, in part, supported by the results of the absorption studies and, in part, by the fact that the titres for the reactions with the tail of heterologous spermatozoa were independent of the presence and concentration of antibody against the tail of human spermatozoa.

\section{ACKNOWLEDGMENTS}

I wish to thank Dr Erik Blom, of the State Veterinary Serum Laboratory, Copenhagen, for valuable advice and discussion both before and during the investigation.

My thanks are also due to the personnel of the Bull-Breeding Centre Østjyden for the supplies of bull spermatozoa.

This investigation was supported by the Danish Medical Research Council (Grant No. 512-215/69).

\section{REFERENCES}

Beck, J. S., Edwards, R. G. \& Young, M. R. (1962) Immune fluorescence technique and the isoantigenicity of mammalian spermatozoa. F. Reprod. Fert. 4, 103.

BEDFoRD, J. M. (1964) Fine structure of the sperm head in ejaculate and uterine spermatozoa of the rabbit. F. Reprod. Fert. 7, 221.

BLom, E. \& BIRGh-Andersen, A. (1961) An 'apical body' in the galea capitis of the normal bull sperm. Nature, Lond. 190, 1127.

Blom, E. \& Birch-ANDERsen, A. (1965) The ultrastructure of the bull sperm. II. The sperm head. Nord. Vet-Med. 17, 193.

EDWARDs, R. G. (1967) Antigenicity of spermatozoa with respect to fertility and infertility. Immunology of spermatozoa and fertilization. Proc. Int. Sym. Varna, Bulgaria, 1969, p. 27. Bulgarian Academy of Sciences Press, Sofia.

FAwCETt, D. W. (1958) The structure of the mammalian spermatozoon. Int. Rev. Cytol. 7, 195.

FAwCETr, D. W. (1970) A comparative view of sperm ultrastructure. Biol. Reprod., Suppl. 2, 90.

HADEK, R. (1963) Study on the fine structure of rabbit sperm. 7. Ultrastruct. Res. 9, 110.

HANCOCK, J. L. (1966) The ultrastructure of mammalian spermatozoa. In: Advances in Reproductive Physiology. Vol. 1, p. 125. Ed. Anne McLaren. Logos Press, London. 
HANSEN, K. B. (1972) Immunofluorescent studies on human spermatozoa. III. Immunoglobulin classes of human spermatozoal antibodies. Clin. exp. Immun. 10, 243.

Hansen, K. B. \& HJort, T. (1971) Immunofluorescent studies on human spermatozoa. II. Characterization of spermatozoal antigens and their occurrence in spermatozoa from the male partners of infertile couples. Clin. exp. Immun. 9, 21.

HJort, T. \& Hansen, K. B. (1971) Immunofluorescent studies on human spermatozoa. I. The detection of different spermatozoal antibodies and their occurrence in normal and infertile women. Clin. exp. Immun. 8, 9.

Johnson, M. H. (1968) Characterization of a natural antibody in normal guinea-pig serum reacting with homologous spermatozoa. F. Reprod. Fert. 16, 503.

KABAT, E. A. \& MAYER, M. M. (1961) Experimental immunochemistry, 2nd edn. Charles C. Thomas, Springfield, Mllinois.

Koefoed-Johnsen, H. H. (1964) Artificial insemination in rabbits. Annual Report, p. 33. Sterility Research Institute, The Royal Veterinary and Agricultural College, Copenhagen.

ManN, T. (1964) The biochemistry of semen and of the male reproductive tract. Methuen London.

O'Donnelt, J. M. \& Symons, D. B. A. (1970) Gentrifugal patterns and morphological variation of bull spermatozoa. F. Reprod. Fert. 23, 41.

Pedersen, H. (1969) Ultrastructure of the ejaculated human sperm. Z. Zellforsch. mikrosk. Anat. 94, 542.

SAACKE, R. G. \& AlmQUisT, J. P. (1964) Ultrastructure of bovine spermatozoa. I. The head of normal, ejaculated sperm. Am. F. Anat. 115, 143.

Symons, D. B. A. (1967) Reaction of spermatozoa with uterine and serum globulin determined by immunofluorescence. F. Reprod. Fert. 14, 163.

Symons, D. B. A. (1968) Immunofuorescent study of the antigenicity of mammalian spermatozoa. Ph.D. thesis, University of London. Cited from the abstract. 